\title{
Translation and psychometric evaluation of the German version of the IcanSDM measure - a cross-sectional study among healthcare professionals
}

Anja Lindig ${ }^{1,2^{*}}$ (D), Pola Hahlweg ${ }^{1,2}$, Eva Christalle ${ }^{1,2}$, Anik Giguere ${ }^{3}$, Martin Härter ${ }^{1,2}$, Olaf von dem Knesebeck ${ }^{2,4}$ and Isabelle Scholl ${ }^{1,2}$

\begin{abstract}
Background: Shared decision-making (SDM) between patients and healthcare professionals (HCPs) is a key component of patient-centred care. To implement SDM in clinical practice and to evaluate its effects, it is helpful to know about HCPs' perception of SDM barriers. The measure IcanSDM was developed in Canada and assesses the perception of SDM barriers. To our knowledge, no equivalent measure exists in German. Therefore, the aim of this study was to translate and adapt the IcanSDM measure to be used by a German speaking population and evaluate its psychometric properties.

Methods: This is a cross-sectional psychometric study based on a secondary analysis of baseline data from a SDM implementation study. The original 8-item IcanSDM was translated into German using a team translation protocol. We assessed comprehensibility via cognitive interviews with $n=11 \mathrm{HCPs}$. Based on results of cognitive interviews, the translated IcanSDM version was revised. Two hundred forty-two HCPs filled out the measure. Psychometric analysis included acceptance (completion rate), item characteristics (response distribution, skewness, item difficulties, corrected item-total correlations, inter-item correlations), factorial structure (confirmatory factor analysis (CFA), model fit), and internal consistency (Cronbach's a).

Results: We translated and adapted the German IcanSDM successfully except for item 8, which had to be revised after the cognitive interviews. Completion rate was $98 \%$. Skewness of the items ranged between -.797 and 1.25 , item difficulties ranged between 21.63 and 70.85, corrected item-total-correlations ranged between .200 and .475, inter-item correlations ranged between .005 and .412. Different models based on CFA results did not provide a valid factorial structure. Cronbach's a ranged between .563 and .651 for different factor models.

(Continued on next page)
\end{abstract}

\footnotetext{
* Correspondence: a.lindig@uke.de

'Department of Medical Psychology, University Medical Center Hamburg-Eppendorf, Martinistraße 52, 20246 Hamburg, Germany

${ }^{2}$ Center of Health Care Research, University Medical Center Hamburg-Eppendorf, Martinistraße 52, 20246 Hamburg, Germany Full list of author information is available at the end of the article
}

(C) The Author(s). 2021 Open Access This article is licensed under a Creative Commons Attribution 4.0 International License, which permits use, sharing, adaptation, distribution and reproduction in any medium or format, as long as you give appropriate credit to the original author(s) and the source, provide a link to the Creative Commons licence, and indicate if changes were made. The images or other third party material in this article are included in the article's Creative Commons licence, unless indicated otherwise in a credit line to the material. If material is not included in the article's Creative Commons licence and your intended use is not permitted by statutory regulation or exceeds the permitted use, you will need to obtain permission directly from the copyright holder. To view a copy of this licence, visit http://creativecommons.org/licenses/by/4.0/ The Creative Commons Public Domain Dedication waiver (http://creativecommons.org/publicdomain/zero/1.0/) applies to the data made available in this article, unless otherwise stated in a credit line to the data. 
(Continued from previous page)

Conclusion: We provide the first German measure for assessing perception of SDM barriers by HCPs. The German IcanSDM is a brief measure with good acceptance. However, we found unsatisfying psychometric properties, which were comparable to results of the original scale. In a next step, the IcanSDM should be further developed and modified and predictive validity should be evaluated.

Keywords: Measuring attitudes regarding shared decision-making, Perspective of healthcare professionals, Psychometrics, Implementation, Shared-decision making, Measurement

\section{Background}

Providing patient-centered care means to respect patients preferences, needs and values and reveals the importance of patients values for clinical decisions [1]. The integration of patient preferences into health care decisions can be realized by shared decision-making (SDM) [2-5]. SDM involves information exchange between healthcare professionals (HCPs) and their patients [6, 7]. HCPs and patients discuss different treatment options based on the best available evidence about the likely benefits and harms. Patients are supported to build informed preferences. Thereby, HCPs and patients are equally and actively involved in the decision-making process and jointly responsible for the decision [7-9]. SDM is especially important in situations in which different and often complex treatment options have a high impact on quality of life (so-called preference-sensitive decisions) [10]. Most patients prefer SDM [11] and benefit from SDM by having better knowledge about their disease and treatment options, less insecurity and decisional conflict and better risk perception [12, 13].

In many countries, the implementation of SDM is supported by public policies [14] and research [15-18]. Nevertheless, SDM is not widely and routinely implemented in the German healthcare system or healthcare systems of other countries yet $[3,19,20]$. A range of barriers that hinder SDM uptake have been reported [21, 22]. Barriers to SDM exist on the health system level (e.g. payment models), organizational level (e.g. lack of resources, lack of leadership support) and the individual level of HCPs and patients (e.g. resistance to change, negative attitudes towards SDM, perception of characteristics of specific clinical situations or patients) [23-26].

Predicting and explaining HCPs' behaviour in the context of SDM uptake can help to develop successful interventions which overcome these barriers. The widelytested Theory of Planned Behaviour (TPB) [27-29] can be helpful to predict and explain HCPs behaviour. According to the TPB, a central factor for behaviour is individuals' intention to perform a behaviour. Behavioural intentions are determined by individuals' attitudes towards the behaviour, subjective norms, and perceived behavioural control [29]. There is a substantial correlation between intention and behaviour [30]. If individuals' intention to perform a specific behaviour is high, they are more willing to try and exert more effort. Additionally, nonmotivational factors like availability of opportunities and resources can influence actual behavioural control and therefore the intention to perform a specific behaviour. According to Fishbein and Ajzen, adoption of a behaviour, like performing SDM, is influenced by knowledge, behavioural intention, and attitudes towards the behaviour [28]. Congruently, there are several studies conducting SDM trainings for HCPs which have shown to be effective in improving HCPs ability of, attitudes towards and confidence in SDM uptake [31-35]. To assess these outcomes, valid and reliable instruments are necessary. There is already a range of measures, which assess the SDM process (i.e. the communicative process between HCP and patient, through which a medical decision is achieved) and SDM outcomes (i.e. satisfaction with decision, decisional regret) [36]. Additionally, a few measures assess other aspects like barriers for SDM uptake [35]. To investigate, why individuals differ in SDM uptake, it is of interest to evaluate determinants of SDM uptake. One of those determinants is the perception of barriers on different levels (e.g. attitude, perceived behavioural control, social norms). HCPs' perception of SDM barriers might indicate HCPs' intention to perform SDM and can be an indicator for differences in SDM performance between HCPs.

Up to now, there is only one measure addressing HCPs' perception of SDM barriers. This new measure IcanSDM was recently developed in Canada for a French-speaking population [35] and translated into English for publication. It measures the perception of barriers for the uptake of SDM and has been psychometrically evaluated by the Canadian study group, revealing a Cronbach's $\alpha$ of above 0.63 and a trend to show sensitivity to change [35]. Although the IcanSDM is still at the beginning of its development and evaluation, it has the potential to be used to assess HCPs' perception of SDM barriers in different healthcare systems. So far, the IcanSDM was not translated to other languages or further validated. In Germany, no comparable measure exists up to now. To be used in German SDM implementation studies, the original IcanSDM has to go through cross-cultural adaptation to reduce the risk of bias due to translation into a different language and assessments in a different culture and setting and at a different time [37]. To do so, items must not only 
be translated linguistically but have to be adapted culturally $[38,39]$. Differences in the cultural context can lead to different validity. Thus, analysis of validity and reliability are necessary to ensure cross-cultural comparability of the measures [38].

Aim of this study was to translate and adapt the IcanSDM measure to be used by a German speaking population and evaluate its psychometric properties.

\section{Methods}

\section{Study design}

For the psychometric evaluation of the IcanSDM we conducted a secondary analysis of cross-sectional data. Cross-sectional data were taken from an implementation study to foster SDM uptake in a German healthcare setting [22]. In this implementation study, we used a stepped wedge design, a variant of a cluster randomized trial $[40,41]$. Thereby, a multi-component SDM implementation program was implemented in three departments of a Comprehensive Cancer Center in Hamburg, Germany. Each department represented a cluster and all physicians and nurses within these clusters were included in the study. Each cluster was first observed under control conditions before it received the intervention in a randomized sequence. It was then observed under intervention condition until the end of the study $[40,41]$. We performed an outcome evaluation at four measurement points as well as a process evaluation throughout all study phases [22]. The psychometric evaluation of the IcanSDM is a secondary analysis of baseline data (control condition) of this SDM implementation study. A waiver of consent for HCPs was obtained from the Ethics Committee, as proposed by current statements of ethical design of implementation research. Study participation was voluntary and HCPs were able to decline participation in the study by not filling out the survey.

To report the results of this study, we used the Authors' Guidelines for Reporting Scale Development and Validation Results by Cabrera-Nguyen as well as the STROBE
Statement for cross-sectional studies. For assessment of comprehensibility as part of content validity, we used the COSMIN criteria (Consensus-based standards for the selection of health measurement instruments).

We previously published the translation and psychometric evaluation of a second measure, the Organizational Readiness for Implementing Chance (ORIC), which was assessed together with the IcanSDM within the same survey [42]. The translation and adaptation procedure as well as the psychometric evaluation of the ORIC and the IcanSDM was done in parallel using very similar methods. For example, both measures were tested within the same cognitive interview sessions. Thus, there might be an overlap in the methods for both measures, ORIC and IcanSDM.

For an overview on all steps of this study, see Table 1.

\section{Measure}

The IcanSDM was developed based on empirical and theoretical work as well as existing literature [28, 35, 43]. Additionally, the design of the scale was guided by the Ottawa Model of Research Use [43] and the Theory of Planned Behaviour [29]. Items of the IcanSDM can be rated on an analogue scale ranging from 0 ("strongly disagree") to 10 ("strongly agree") [35]. In a first version, the original IcanSDM consisted of eleven items. Two of these items have shown to reduce internal consistency, one item was not understood by participants in a qualitative item analysis and also has shown to reduce internal consistency. These three items were excluded for further development and validation of the scale [35]. Items were developed in French and translated into English by a translator for international publication. For the English items of the 8-item scale, see Table 4 of the Results section. The authors of the original IcanSDM are the only ones who provided psychometric data for the IcanSDM up to now. Their analysis revealed a Cronbach's $\alpha$ of above 0.63 and a trend to sensitivity to change [35]. Additionally, they assumed that the measure has a onedimensional structure, but the factorial structure of the

Table 1 Overview of the process of this study 1 Translation according to TRAPD protocol Translation: Two independent translations were produced.

Review: A third bilingual reviewer compared the two translations and decided for one of the translations or suggested a third translation.

Adjudication: Both translators and the reviewer discussed the translations and suggestions and decided for a final translation.

Documentation: Draft translations, exchange of comments between the translators and decisions for a final translation was documented.

2 Assessment of comprehensibility by two rounds of cognitive interviews

3 Psychometric evaluation by secondary analysis of cross-sectional data
Convenience sample including nurses and physicians of a Comprehensive Cancer Center in Hamburg, Germany as well as psychologists of the out-patient clinic for Psycho-oncology at the University Medical Center Hamburg - Eppendorf (UKE).

The sample includes all physicians and nursed working in one of three departments of a Comprehensive Cancer Center in Hamburg, Germany 
IcanSDM has not been evaluated up to now. Giguere et al. [35] recommend to calculate a sum score for all items. Higher scores indicate stronger perception of barriers, which might be associated with lower ability to adopt SDM.

\section{Translation}

To be published in an international journal, the original French IcanSDM was translated into English by an official translator. We translated the English IcanSDM into German. Thereby we used the team translation protocol TRAPD (Translation, Review, Adjudication, Pretesting and Documentation [44-47]). As a first step, two team members (AL, NE, cp. list of abbreviations), independently translated the English IcanSDM including the response scale, the introduction and all eight items into German. In a second step, a third team member (IS) reviewed the translations of AL and NE. She decided for one of the two versions or suggested a third version. Additionally, another team member (SZ, cp. list of abbreviations) reviewed the translations by $\mathrm{AL}, \mathrm{NE}$, and IS and made additional suggestions for single items. All team members were proficient in English and German. In a final discussion, AL, NE, and IS reached a consensus on a final German IcanSDM version to be further tested for comprehensibility.

\section{Assessment of comprehensibility}

To measure if the IcanSDM items reflect the construct of perception of SDM barriers, we assessed content validity. Thereby we followed COSMIN criteria (Consensus-based standards for the selection of health measurement instruments) [48, 49], which define content validity as relevance, comprehensiveness, and comprehensibility of the measures items and scales. When translating an existing measure, it is most interesting to assess comprehensibility. Thus, we aimed to evaluate if items are worded appropriately and understood by HCPs as intended by the developers of the measure..

To assess comprehensibility, we executed two rounds of cognitive interviews. Items, which showed less comprehensibility in the first round of cognitive interviews were modified by the study team and again tested in a second round. We recruited a convenience sample of HCPs including nurses, physicians, and psychologists who worked at a Comprehensive Cancer Center in Hamburg, Germany. We excluded HCPs who worked in clinics which take part in the SDM implementation study, where the IcanSDM was planned to be applied. We invited physicians and nurses by sending an e-mail to head physicians and leading nurses of clinics within the Comprehensive Cancer Center including the request to forward the invitation to physicians and nurses of the clinics. Psychologists were recruited via the out-patient clinic for Psycho- oncology at the University Medical Center Hamburg Eppendorf (UKE). AL and PH conducted the interviews, which took place in a seminar room of the Department of Medical Psychology at the University Medical Center Hamburg - Eppendorf (UKE). We developed an interview guide, including verbal probing and paraphrasing $[50,51]$. Cognitive interviews were audio-recorded and transcribed verbatim. In a first round of cognitive interviews, participants were asked for their comprehension of the response scale, the introduction as well as one translated version for item 1 to item 7 and two translated versions for item 8. Afterwards, we extracted participants' comments from the transcripts and discussed them within the study team (AL, PH, IS). Items of the German IcanSDM, which were not well understood by participants, were adapted accordingly. These revised items were tested in a second round of cognitive interviews. Afterwards, we again had to discuss translation and further adaption of one item (item 8). For this step, we involved one of the authors of the original IcanSDM measure (AG) and discussed the meaning and the background literature of item 8 . As a consequence of our discussion, AG revised item 8 of the original French and English IcanSDM to increase comprehensibility by participants. We again translated this revised item 8 using the same approach as described above.

We used SPSS (IBM SPSS Statistics, Version 23) to calculate descriptive statistics of participants' demographic characteristics.

\section{Psychometric evaluation \\ Data collection}

Within the scope of a SDM implementation study [22], we conducted a secondary analysis of cross-sectional data. The IcanSDM was one of several measures [52-54] within one survey (27 items), which also assessed demographic characteristics (5 items).

We included all physicians and nurses working at one of the three departments of one Comprehensive Cancer Center in Germany, which participated in the SDM implementation study [22]. We expected physicians and nurses with diverse demographic characteristics including different sex, age and work experience taking part in this study. Physicians and nurses received the survey either (1) personally by a study team member, (2) via supervising nurses, or (3) via mail. After filling out the survey, participants had the options to either (1) personally hand the survey over to a study team member or (2) to send it back via mail. For quality control, we entered $20 \%$ of the data double and blinded into SPSS (IBM SPSS Statistics, Version 23).

\section{Data analysis}

To assess acceptance of the IcanSDM, we evaluated the completion rate and calculated missing data frequencies 
per item, per case, and for the overall measure. For further psychometric evaluation, we excluded cases with more than $30 \%$ of IcanSDM items missing (3 items and more) [55]. Missing data for the other cases were replaced by means of the single items. We calculated descriptive statistics for demographic characteristics of participants.

For item analysis, we examined response distribution end evaluated floor and ceiling effects [56]. For floor and ceiling effects we analysed item difficulties $[57,58]$ as well as the skewness of response distribution [59]. Additionally we calculated item means and standard deviations, corrected item-total correlations [60, 61], and inter-item correlations $[60,61]$.

To test assumptions for performing a factor analysis, Kaiser-Meyer-Olkin (KMO) measure of sampling adequacy and Bartlett's test of sphericity were calculated $[57,60]$. Analysis of the factorial structure of the IcanSDM has an exploratory character based on assumptions of Giguere et al. They calculated psychometric analysis of the French IcanSDM based on an assumed one-factorial structure [35]. Accordingly, we a priori hypothesized a one-factorial structure of the German IcanSDM. A confirmatory factor analysis (CFA) with Maximum Likelihood Estimates and one factor was applied for the whole data set (model 1). During factor analysis we modified this model stepwise (model 2 and model 3). For the interpretation of factor loadings and definition of cut-offs for suitable factor models, different criteria exist [59, 62-64]. Therefore, interpretation of model quality might differ depending on the underlying theory and applied cut-off values. We decided to use the established and less conservative criterion of .40 for sample sizes above $n=200$ as a cut-off for acceptable factor loadings $[63,64]$. We calculated global goodness of fit indices: discrepancy chi-squared statistic $\left(\mathrm{Chi}^{2}\right)$, degree of freedom (df), normed chi-squared statistic $\left(\mathrm{Chi}^{2} / \mathrm{df}\right)$, Comparative Fit Index (CFI), Tucker-Lewis Index (TLI), Root Mean Square Error of Approximation (RMSEA), as well as the Akaike Information Criterion (AIC) and Parsimonious Normed Fit Index (PNFI), which hep to analyse model complexity. We used established criteria to interpret the estimated model fits [63, 65-67], see Table 2.

Because factor loadings and model fit indices for the one-factor model were not satisfying, we applied two alternative models (model 2 and model 3 ) to the data based on analysis of modification indices and content of specific items (see Results section).

We assessed internal consistency by Cronbach's alpha coefficient $(\alpha)[57,61,70]$. Since this was a secondary analysis of cross-sectional data, several psychometric parameters like convergent or divergent validity were not analysable.
For a detailed overview on performed data analysis, see Table 2.

For analysis of demographic data, completion rate and item analysis we used SPSS (IBM SPSS Statistics, Version 23). For CFA and calculation of model fit indices we used Amos (IBM SPSS Amos 22.0.0).

\section{Results}

\section{Translation}

Both translators (AL and NE) and the reviewer (IS) came to similar translations of the IcanSDM. Only slight differences in sentence structure or single words without differences in meaning were found. SZ reviewed all translations and added comments and suggestions for items 2, 4, and 8. During the following team discussion, we reached consensus for translation of all items, the response scale, and the survey introduction.

\section{Assessment of comprehensibility}

We conducted cognitive interviews with $n=11$ participants to test the German IcanSDM for comprehensibility. For demographic data of participants see Table 3.

The first round of cognitive interviews $(n=7)$ revealed that items $1,2,3,4,7$, and the response scale were well understood. We found lower comprehensibility for the survey instruction, item 5, 6 and 8 . The survey instruction and the three items were tested again in a second round of cognitive interviews $(n=4)$.

When filling out the measure, some participants of the first round of cognitive interviews did not refer to their own opinion and think about their current work place. We concluded that the survey instruction might not be precise enough. The revised survey instruction was well understood by all participants of the second round of cognitive interviews.

For item 5 ('Shared decision making takes up too many resources.'), participants of the first round of cognitive interviews suggested to add 'e.g. time, staff' as examples for the term 'resources' to increase comprehensibility of this term. After changing the item accordingly, it was well understood by all participants of the second round of cognitive interviews.

For item 6 ('Shared decision making is inconsistent with clinical practice guidelines.'), some participants of the first round of cognitive interviews were not sure about the meaning of the term 'clinical practice guidelines'. For the second round of cognitive interviews, we therefor tested item 6 again as well as an alternative version with a slight change in wording. Since the original translation of item 6 was now understood best, we decided to use this translation for the final measure.

For nearly all participants of the first round of cognitive interviews, the meaning of item 8 ('The shared decision-making process highlights the uncertainty 
Table 2 Psychometric analysis conducted

\begin{tabular}{|c|c|}
\hline Psychometric measure & Criteria \\
\hline $\begin{array}{l}\text { Kaiser-Meyer-Olkin (KMO) measure of sampling } \\
\text { adequacy and Bartlett's test of sphericity }\end{array}$ & $\begin{array}{l}\text { These tests ensure that correlations between variables can be accounted for by a smaller set } \\
\text { of factors [60]. KMO value should be higher than } .05 \text { and Bartlett's test value should be less } \\
\text { than } .05 \text { to fulfil the criteria for calculating a factor analysis }[57,60] \text {. }\end{array}$ \\
\hline Normed chi-squared statistic (Chi²/df) & $\begin{array}{l}\mathrm{Chi}^{2} / \mathrm{df} \text { is an indicator for model fit, dependent on sample size and should be as small as } \\
\text { possible. A ratio between } 2 \text { and } 3 \text { indicate a good data fit [67]. }\end{array}$ \\
\hline Comparative fit indexes (CFI) & $\begin{array}{l}\text { CFIs is an indicator for model fit. It ranges from } 0 \text { to } 1 \text { and higher values indicate better fit. } \\
\text { Values above } .95 \text { indicate a good model fit }[65,68] \text {. }\end{array}$ \\
\hline Tucker-Lewis Index (TLI) & $\begin{array}{l}\text { TLI is an indicator for model fit. It corrects for complexity of the model and is sensitive to } \\
\text { small sample sizes. Values above } .95 \text { indicate good fit [66]. }\end{array}$ \\
\hline Root mean square error of approximation (RMSEA) & $\begin{array}{l}\text { RMSEA is an absolute index which describes closeness to fit. Values below .05 indicate a } \\
\text { good fit, values between } .05 \text { and } .08 \text { indicate an adequate fit, values between } .08 \text { and } 1 \\
\text { indicate a moderate fit and values above } 1 \text { are unacceptable [69]. }\end{array}$ \\
\hline Akaike Information Criterion (AIC) & $\begin{array}{l}\text { AIC is a parsimony model fit index. It can be used to compare fit of competing models with } \\
\text { smaller values indicating better fit }[65,67] \text {. }\end{array}$ \\
\hline Parsimonious Normed Fit Index (PNFI) & $\begin{array}{l}\text { PNFI is a parsimony model fit index. It ranges between } 0 \text { and } 1 \text { and higher values indicate a } \\
\text { more parsimonious fit [67]. No threshold levels are recommended and it has to be analysed } \\
\text { in combination with other goodness of fit indices [65]. }\end{array}$ \\
\hline Analysis of frequencies for item response distributions & $\begin{array}{l}\text { Floor and ceiling effects were assumed if more than } 15 \% \text { of participants choose the lowest } \\
\text { or highest possible score [56]. For analogue scales, no cut-off values exist. According to Bortz } \\
\& \text { Döring, items with difficulties below } 20 \% \text { show a floor effect, items with difficulties above } \\
80 \% \text { show a ceiling effect. Additionally, a skewness below - } 2 \text { indicates a floor effect, a skew- } \\
\text { ness above }+2 \text { indicates a ceiling effect [59]. }\end{array}$ \\
\hline Corrected item-total correlations & $\begin{array}{l}\text { If items correlate with the total score of above } .30 \text {, they measure the same underlying } \\
\text { concept. Items with lower correlations should be removed because they do not add } \\
\text { exploratory power to the measure }[60,61] \text {. }\end{array}$ \\
\hline Item difficulties & $\begin{array}{l}\text { Item difficulties are calculated by dividing item means by the maximal value of the answer } \\
\text { range }(0-10) \text { and multiplying it with } 100 \text {. Item difficulty should be near to } 50 \% \text {, and items } \\
\text { should not differ much in their difficulty level [57]. }\end{array}$ \\
\hline Inter-item correlations & $\begin{array}{l}\text { Inter-item correlations ensure association between items. High inter-item correlations of } \\
\text { above } .80 \text { indicate that items ask the same questions and might be redundant [60, 61]. }\end{array}$ \\
\hline Cronbach's a & $\begin{array}{l}\text { Cronbach's } a \text { is a measure for reliability and internal consistency. A value of at least } .70 \text { is } \\
\text { acceptable and higher coefficients indicate a more stable measure }[57,60,70] .\end{array}$ \\
\hline
\end{tabular}

Note: This table has been adapted from Lindig et al. [53]

associated with interventions. This could affect treatment adherence.') was not clear. Especially the term 'treatment adherence' was not familiar for participating nurses and the sentence structure was confusing for some participants. Some participants suggested to rather use the term 'compliance' because it is more commonly used in daily practice. Nevertheless, we discussed that 'treatment adherence' is the less stigmatic term. We therefor rephrased the item and tested two new versions in the second round of cognitive interviews. In the first version of revised item 8 we used the German phrase 'Behandlungstreue', which seemed to be better understood compared to 'Behandlungsadhärenz' (both translate into 'treatment adherence' in English). In the second version of item 8 we used the phrase 'compliance' according to suggestions of some participants. Participants of the second round of cognitive interviews still differ in their comprehension of this item. We had to conclude that item 8 could not be translated successfully indicating reduced comprehensibility according to COSMIN criteria [48]. For the subsequent revision in collaboration with AG, we changed the structure of the English and French item and left out the term 'treatment adherence': 'During shared decision making, the patient becomes aware of the uncertainty associated with interventions and might become confused'. After translation by the study team, we reached consensus on a final version of item 8 . This item was not further tested in cognitive interviews.

For the original version of the IcanSDM and the versions used for both rounds of cognitive interviews, see Table 4. For the final German IcanSDM measure, see Additional file 1.

Some nurses reported during cognitive interviews, that the term "shared decision-making" (German: "Partizipative Entscheidungsfindung") was new to them and they had not heard about the concept of SDM before. Thus, a definition of SDM was provided in the introduction of the survey. 
Table 3 Demographic data of participants of cognitive interviews $(n=11)$

\begin{tabular}{ll}
\hline & Frequencies for $\mathbf{n = 1 1}$ \\
\hline Age & 1 \\
$<30$ years & 3 \\
$31-40$ years & 3 \\
$41-50$ years & 4 \\
$>50$ years & \\
Sex & 9 \\
Female & 2 \\
Male & \\
Profession & \\
Nurse & 8 \\
Physician & 2 \\
Psychooncologist & 3 \\
Work experience in health care & \\
$>5$ years & 3 \\
5-10 years & 4 \\
11-20 years & 3 \\
$>$ 20 years & 1 \\
\hline multiple answers possible &
\end{tabular}

\section{Psychometric evaluation}

\section{Missing data analysis and analysis of acceptance}

We collected data of 243 HCPs. For the whole data set, 20 missing values could be observed. Resulting completion rates per item ranged between $97.95 \%$ (five missing values for item 6 and 7) and 99.59\% (one missing value for item 1, 3, and 5) (see Table 6). Missing values could be observed for 11 cases (eight cases with one missing value, two cases with two missing values, and one case for which all 8 items were missing). Accordingly, 98.97\% of all items over all participants were answered (1924 of 1944 data points) and $95.47 \%$ of the respondents completely filled out the measure. One case $(0.4 \%$ of all cases $)$ had to be excluded from further analysis because all IcanSDM items were missing [55]. For the other cases, $0.62 \%$ of all items (11 of 1936 data points) were missing and replaced by item means. Therefore, data of $242 \mathrm{HCPs}$ were included in the psychometric analysis.

\section{Sample characteristics}

Table 5 gives an overview of participants' demographic characteristics. The majority of the 242 HCPs were between 31 and 40 years old (36.0\%), female (71.1\%), were nurses $(57.0 \%)$, and had work experience of less than 5 years $(43.8 \%)$.

\section{Analysis of the IcanSDM items}

Response distributions for all items are presented in Fig. 1. Observation of response distribution showed a trend to floor effects for items 6 and 7 and a slight trend to a ceiling effect for item 3. Table 6 shows means and standard deviations, skewness, item difficulties, acceptance (completion rates), and item discrimination (corrected item-total correlations) of the eight items. Means ranged between 2.16 (item 7) and 7.09 (item 1) on a scale from 0 to 10 . Accordingly, item difficulties ranged from 21.63 (item 7) to 70.85 (item 1). Skewness for the items are acceptable since values are between -.797 (item 1) and 1.25 (item 7) [59]. Skewness and item difficulties indicate that no floor or ceiling effects can be observed for our data [57-59]. Corrected item-total correlations ranged from .200 (item 1) to .475 (item 4), and inter-item correlations from .005 (item 3 / item 6) to .412 (item 3 / item 5 , see Table 7).

\section{Factor analysis}

Assumptions for factor analysis were fulfilled [48, 57, 60]. KMO measure was .698 and Bartlett's test of sphericity resulted in $\mathrm{X}^{2}=247.43, p<.001[57,60]$.

For model 1, we assumed a one-factorial structure without correlations between items based on the evaluation of the original measure [35]. CFA for this model showed standardized factor loadings between .25 (item 1) and .62 (item 5) with three items showing factor loadings below .40 (items 1, 3, and 6; see Fig. 2). This indicated that some items did not fit to the predefined factor $[59,63,64]$. A Chi ${ }^{2} / \mathrm{df}$ of above 3.0, CFI, TLI of below .95, and RMSEA of above .1 did not meet cut-offs, indicating that the one-factor model did not fit to the data [65-67, 69] (see Table 8). Additionally, observed modification indices between item 3 and item 8 (8.42) as well as item 6 and item 7 (16.85) were high. This indicates a model fit improvement if correlations between these items are allowed. Thus, correlations between items 3 and 8 as well as items 6 and 7 could be postulated. We also analysed these items on the content level. Item 3 and item 8 both address the barrier that SDM might not be suitable for (all) patients in all clinical situations. Compared to all other items, which address the interaction between HCP and patient, item 6 and item 7 both target the macro level. We therefore calculated an alternative model with correlated residuals between item 3 and item 8 as well as between item 6 and item 7 (model 2).

Model 2 came along with factor loadings between .29 (item 1) and .66 (item 5) with three items showing factor loadings below .40 (items 1, 3 and 6; see Fig. 3). Model fits for model 2 were better than for model 1 (see Table 8). Values for $\mathrm{Chi}^{2} / \mathrm{df}$ and RMSEA were acceptable, values for CFI and TLI were still not acceptable [65-67, 69]. Because 
Table 4 English version of the items and German translation

\begin{tabular}{|c|c|c|c|}
\hline & Original version & $\begin{array}{l}\text { Versions used for the first round of } \\
\text { cognitive interviews }\end{array}$ & $\begin{array}{l}\text { Versions used for the second round of } \\
\text { cognitive interviews }\end{array}$ \\
\hline Response scale & $\begin{array}{l}\text { strongly disagree } \\
\text { strongly agree }\end{array}$ & $\begin{array}{l}\text { Stimme überhaupt nicht zu. } \\
\text { Stimme völlig zu. }\end{array}$ & 1 \\
\hline Introduction & $\begin{array}{l}\text { Please indicate how much you agree or } \\
\text { disagree with each of the following } \\
\text { statements relative to shared decision } \\
\text { making. There is no right or wrong } \\
\text { answer. }\end{array}$ & $\begin{array}{l}\text { Bitte geben Sie an, wie stark Sie jeder der } \\
\text { folgenden Aussagen zur partizipativen } \\
\text { Entscheidungsfindung zustimmen. Es gibt } \\
\text { keine richtige oder falsche Antwort. }\end{array}$ & $\begin{array}{l}\text { Bitte geben Sie durch ein Kreuz auf der } \\
\text { Linie an, wie stark Sie jeder der folgenden } \\
\text { Aussagen zustimmen. Geben sie Ihre } \\
\text { persönliche Meinung an und beziehen Sie } \\
\text { sich auf Ihren aktuellen Arbeitsplatz. }\end{array}$ \\
\hline Item 1 & $\begin{array}{l}\text { Shared decision - making results in longer } \\
\text { clinical encounters. }\end{array}$ & $\begin{array}{l}\text { Partizipative Entscheidungsfindung führt } \\
\text { zu längeren Gesprächen mit Patientinnen } \\
\text { und Patienten. }\end{array}$ & / \\
\hline Item 2 & $\begin{array}{l}\text { Patients often prefer that the clinician } \\
\text { make the decision. }\end{array}$ & $\begin{array}{l}\text { Patientinnen und Patienten finden es } \\
\text { häufig besser, dass der Arzt / die Ärztin } \\
\text { die Entscheidung trifft. }\end{array}$ & / \\
\hline Item 3 & $\begin{array}{l}\text { Shared decision making does not apply to } \\
\text { all patients, nor does it apply to all clinical } \\
\text { situations. }\end{array}$ & $\begin{array}{l}\text { Partizipative Entscheidungsfindung kann } \\
\text { man weder bei allen Patientinnen und } \\
\text { Patienten noch in allen klinischen } \\
\text { Situationen anwenden. }\end{array}$ & / \\
\hline Item 4 & $\begin{array}{l}\text { Communicating scientific data to patients } \\
\text { is too complex. }\end{array}$ & $\begin{array}{l}\text { Es ist zu aufwendig, Patientinnen und } \\
\text { Patienten wissenschaftliche Daten zu } \\
\text { vermitteln. }\end{array}$ & / \\
\hline Item 5 & $\begin{array}{l}\text { Shared decision making takes up too } \\
\text { many resources. }\end{array}$ & $\begin{array}{l}\text { Partizipative Entscheidungsfindung } \\
\text { beansprucht zu viele Ressourcen. }\end{array}$ & $\begin{array}{l}\text { Partizipative Entscheidungsfindung } \\
\text { beansprucht zu viele Ressourcen (z.B. Zeit, } \\
\text { Personal). }\end{array}$ \\
\hline \multirow[t]{2}{*}{ Item 6} & \multirow[t]{2}{*}{$\begin{array}{l}\text { Shared decision making is inconsistent } \\
\text { with clinical practice guidelines. }\end{array}$} & \multirow[t]{2}{*}{$\begin{array}{l}\text { Partizipative Entscheidungsfindung ist } \\
\text { nicht mit klinischen Leitlinien vereinbar. }\end{array}$} & $\begin{array}{l}\text { Partizipative Entscheidungsfindung ist nicht } \\
\text { mit klinischen Leitlinien vereinbar. }\end{array}$ \\
\hline & & & $\begin{array}{l}\text { Partizipative Entscheidungsfindung ist nicht } \\
\text { mit den Vorgaben in klinischen Leitlinien } \\
\text { vereinbar. }\end{array}$ \\
\hline Item 7 & $\begin{array}{l}\text { Shared decision making is just a passing } \\
\text { trend. }\end{array}$ & $\begin{array}{l}\text { Partizipative Entscheidungsfindung ist nur } \\
\text { ein vorübergehender Trend. }\end{array}$ & / \\
\hline \multirow[t]{2}{*}{ Item 8} & \multirow[t]{2}{*}{$\begin{array}{l}\text { The shared decision-making process high- } \\
\text { lights the uncertainty associated with in- } \\
\text { terventions. This could affect treatment } \\
\text { adherence. }\end{array}$} & $\begin{array}{l}\text { Der Prozess der partizipativen } \\
\text { Entscheidungsfindung beleuchtet die } \\
\text { Unsicherheit, die mit Behandlungen } \\
\text { verbunden ist. Dies könnte die } \\
\text { Behandlungsadhärenz beeinflussen. }\end{array}$ & $\begin{array}{l}\text { Partizipative Entscheidungsfindung macht } \\
\text { vorhandene Unsicherheiten in Bezug auf } \\
\text { Behandlungen deutlich. Dies könnte die } \\
\text { Behandlungstreue beeinflussen. }\end{array}$ \\
\hline & & $\begin{array}{l}\text { Der Prozess der partizipativen } \\
\text { Entscheidungsfindung beleuchtet die } \\
\text { Unsicherheit, die mit Behandlungen } \\
\text { verbunden ist. Dies könnte die } \\
\text { Behandlungstreue beeinflussen. }\end{array}$ & $\begin{array}{l}\text { Partizipative Entscheidungsfindung macht } \\
\text { vorhandene Unsicherheiten in Bezug auf } \\
\text { Behandlungen deutlich. Dies könnte die } \\
\text { Compliance beeinflussen. }\end{array}$ \\
\hline
\end{tabular}

of its unacceptable factor loadings and model fits, we had to conclude that model 2 also does not fit to the data. Since item 6 and item 7 fundamentally differ from all other items (they target the macro level), we tested another model with two factors (model 3). Factor 1 included items 1 to 5 and item 8 , and factor 2 included items 6 and 7. We assumed a correlation between both factors.

Model 3 came along with factor loadings between .29 (item 1) and .76 (item 8) with two items showing factor loadings below .40 (items 1 and 3; see Fig. 4). Correlation between both factors was .58. Model fits for model 3 were comparable to model fits of model 2 , but factor loadings were better for model 3 [59, 63, 64] (see Table 8).

\section{Analysis of internal consistency}

Cronbach's $\alpha$ is .651 for the one-factor models 1 and 2 . For model 3 with two factors, Cronbach's $\alpha$ for factor 1 is .613 and Cronbach's $\alpha$ for factor 2 is .563 .

\section{Discussion}

The IcanSDM is a brief measure to assess HCPs' perceptions of SDM barriers. It was recently developed and evaluated in Canada for French speaking physicians and translated into English [35]. Aim of this study was to translate and adapt the English IcanSDM to be used by a German speaking population and evaluate its psychometric properties. 
Table 5 Demographic characteristics of participants ( $n=242$ healthcare professionals)

\begin{tabular}{|c|c|}
\hline & N (\%) \\
\hline \multicolumn{2}{|l|}{ Age } \\
\hline$<30$ years & $76(31.4)$ \\
\hline $31-40$ years & $87(36.0)$ \\
\hline $41-50$ years & $44(18.2)$ \\
\hline$>50$ years & $29(12.0)$ \\
\hline Missings & $6(2.5)$ \\
\hline \multicolumn{2}{|l|}{ Sex } \\
\hline Female & $172(71.1)$ \\
\hline Male & $60(24.8)$ \\
\hline Different sex or preferred not to answer this question & $4(1.7)$ \\
\hline Missings & $6(2.5)$ \\
\hline \multicolumn{2}{|l|}{ Profession } \\
\hline Nurse & $138(57.0)$ \\
\hline Physician & $99(40.9)$ \\
\hline Junior physician & $70(28.9)$ \\
\hline Senior physician & $29(12.0)$ \\
\hline Missings & $5(2.1)$ \\
\hline \multicolumn{2}{|l|}{ Work experience } \\
\hline$<5$ years & $106(43.8)$ \\
\hline $5-10$ years & $50(20.7)$ \\
\hline $11-20$ years & $43(17.8)$ \\
\hline$>20$ years & $34(14.0)$ \\
\hline Missings & $9(3.7)$ \\
\hline
\end{tabular}

Translation and psychometric evaluation

Study team members involved in translation reached consensus for the translation of the IcanSDM. While items 1 to 7 and the survey instruction were well understood by all participants of cognitive interviews, item 8 had to be reworded. Comprehensibility of the final item 8 was not further tested in cognitive interviews, thus content validity of this item remained unclear. During cognitive interviews, we noticed that some participants, especially nurses, were less familiar with the concept of SDM than others. This is notable since SDM is promoted by the German government and research for many years [71-74]. Several studies could show that HCPs often lack a full conceptual understanding of SDM while at the same time having a positive attitude towards SDM [33, 75-79]. But it has to be kept in mind that limited knowledge about SDM might also be a barrier to perform SDM [79]. In terms of cross-cultural translation of a SDM measure, this underlines the importance of assessing knowledge about the construct and specific terms of the measure in the target language and compare it with the original language [38]. For filling out the IcanSDM it is crucial to have an idea about the concept of SDM. Therefore, we would recommend to provide a definition of SDM in the introduction of the measure.

In the following CFA, we could not confirm the a priori hypothesized one-factorial structure for the German IcanSDM (model 1) or an alternative model with correlations between item 3 and item 8 as well as item 6 and item 7 (model 2). A model with two factors (model 3) showed a correlation of .58 between both factors, which indicates that the factors are associated but capture different aspects of SDM barriers. This is congruent with results of Giguere et al. [35], who found a shift in item response distribution towards a more positive attitude after training for all items except for items 6 and 7 . The authors concluded that training might have less impact on rating of these items. This underlines our assumption that item 6 and 7 rather cover SDM barriers on the macro level, where perceived behavioural control might be reduced compared to other items. Nevertheless, model 3 did not show satisfying model fits [59, 63, 64]. To conclude, we could not provide a valid model for the German IcanSDM at this point of analysis. This might be due to an insufficient cross-cultural translation process [38]. There might be differences in the concepts measured by the IcanSDM in the original and the target language. Additionally, we may missed to address differences in the German and Canadian health care settings. Furthermore, we had to deal with some time and financial constraints because the IcanSDM was planned to be used in an SDM implementation study [22]. For practical reasons, we therefore did not pretest the measure. A flawed cross-cultural adaptation process might result in reduced comparability of the Canadian and German IcanSDM [38, 39]. Future studies should explore all aspects of cross-cultural validity and the needs to adapt the measurement for the cultural context of the German health care system. Thereby, it should be assessed whether the IcanSDM items are relevant and comprehensive to assess SDM barriers in Germany and whether results are comparable with samples from other countries and of other languages.

The German IcanSDM was found to be well-accepted by study participants. Items, which had low factor loadings in the factor analysis also showed conspicuous characteristics in item analysis. Observed floor and ceiling effects indicated that items 6 and 7 might not be perceived as barriers for SDM in the German healthcare system and item 3 might be phrased too conservative. Corrected item-total correlations of items 1, 3 and 6 indicated that these items do not measure the underlying concept $[60,61]$. Criteria for good item difficulties were not met for items $1,6,7$, and 8 [57]. Inter-item correlations indicated that all items add additional information but are less connected to each other $[60,61]$. This also 

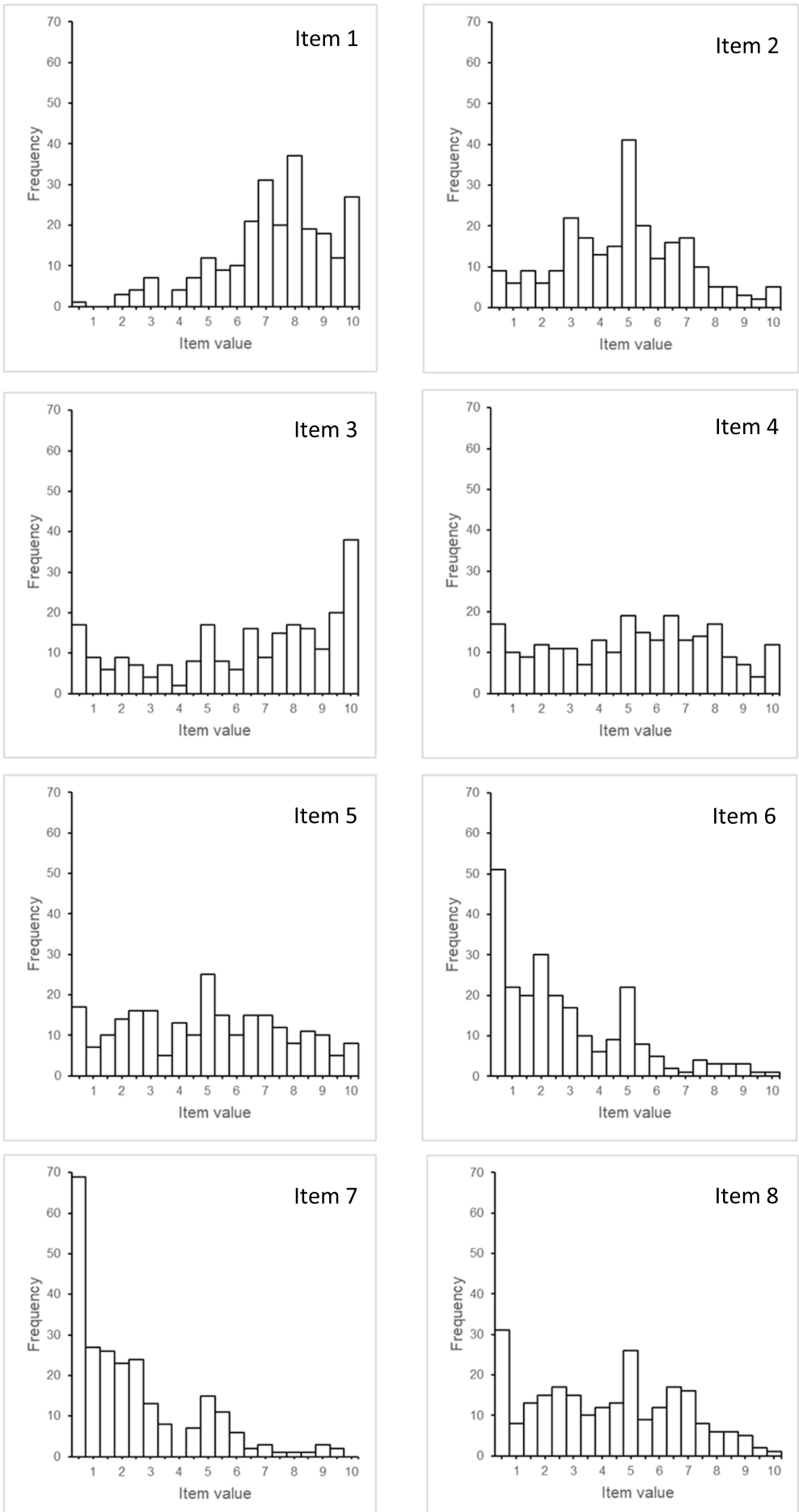

Fig. 1 Response distribution for the IcanSDM items ( $n=242$ healthcare professionals). Data were clustered in steps of 0.5

results in low values for internal consistency which are comparable to the original scale [57, 60, 70]. Nevertheless, since no valid model could be found for the German IcanSDM, values for internal consistency should be interpreted with caution.
Use of the IcanSDM as a measure for perception of SDM barriers by HCPs

The authors of the French IcanSDM hypothesized that clinicians' perception of SDM barriers could indicate their perceived ability to adopt SDM. Giguere et al. [35] 
Table 6 Means, standard deviation, skewness, item difficulty, acceptance and item discrimination of the German IcanSDM ( $n=242$ healthcare professionals)

\begin{tabular}{|c|c|c|c|c|c|c|}
\hline & Items & $\begin{array}{l}\text { Mean } \\
\text { (SD) }\end{array}$ & Skewness & $\begin{array}{l}\text { Item } \\
\text { difficulty }\end{array}$ & $\begin{array}{l}\text { Acceptance } \\
\text { (Completion } \\
\text { rate in \%) }\end{array}$ & $\begin{array}{l}\text { Item discrimination } \\
\text { (corrected item-total } \\
\text { correlation) }\end{array}$ \\
\hline 1 & Shared decision-making results in longer clinical encounters. & $\begin{array}{l}7.08 \\
(1.97)\end{array}$ & -.797 & 70.85 & 99.59 & .200 \\
\hline 2 & Patients often prefer that the clinician makes the decision. & $\begin{array}{l}4.64 \\
(2.21)\end{array}$ & .071 & 46.44 & 99.18 & .347 \\
\hline 3 & $\begin{array}{l}\text { Shared decision-making does not apply to all patients, nor does it } \\
\text { apply to all clinical situations. }\end{array}$ & $\begin{array}{l}6.13 \\
(3.16)\end{array}$ & -.5 & 61.25 & 99.59 & .257 \\
\hline 4 & Communicating scientific data to patients is too complex. & $\begin{array}{l}4.94 \\
(2.76)\end{array}$ & -.106 & 49.39 & 99.18 & .475 \\
\hline 5 & Shared decision-making takes up too many resources. & $\begin{array}{l}4.75 \\
(2.72)\end{array}$ & .046 & 47.47 & 99.59 & .459 \\
\hline 6 & $\begin{array}{l}\text { Shared decision-making is inconsistent with clinical practice } \\
\text { guidelines. }\end{array}$ & $\begin{array}{l}2.58 \\
(2.25)\end{array}$ & 1.00 & 25.79 & 97.94 & .256 \\
\hline 7 & Shared decision-making is just a passing trend. & $\begin{array}{l}2.16 \\
(2.16)\end{array}$ & 1.25 & 21.63 & 97.94 & .389 \\
\hline 8 & $\begin{array}{l}\text { During shared decision-making, the patient becomes aware of the } \\
\text { uncertainty associated with interventions and might become } \\
\text { confused. }\end{array}$ & $\begin{array}{l}3.97 \\
(2.53)\end{array}$ & .152 & 39.70 & 98.77 & .383 \\
\hline
\end{tabular}

evaluated the psychometric properties of the IcanSDM in a small sample and described a trend towards change sensitivity but also conspicuous item characteristics and suboptimal low values for Cronbach's $\alpha$. In our study, we replicated these findings with an adequate sample size, indicating that the different items may not measure the same underlying construct. This might be a result of the fact that the items target SDM barriers on different levels (e.g. attitude, organizational level, social norms). All in all, the results indicate that the construct that the IcanSDM claims to measure needs revision. Thus, this limits interpretation of findings for the original scale and comparison with the German IcanSDM.

Therefore, we recommend to further evaluate and revise the underlying construct of the original IcanSDM scale as well as the German IcanSDM scale. It should also be considered to add items to assess perceived behavioural control upon adoption of SDM as well as to add more items which describe barriers at the macro level. Additionally, during the development of the measure, the authors of the original IcanSDM deleted three items due to their negative effects on internal consistency and comprehensiveness of the measure. These items might be relevant for the German IcanSDM and should be considered for use in the German IcanSDM. To use the revised original IcanSDM in German, it should go through a systematic cross-cultural translation process [39]. Afterwards, the revised German IcanSDM scale should be assessed with a new sample of HCPs. Also, comparisons with other measures to test for convergent and divergent validity might help to evaluate and improve the quality of the scale.

In a next step, it is important to assess if the IcanSDM can reflect HCPs' perceived ability to adopt SDM and therefore predict future behaviour of HCPs. Thereby, results of the French and German IcanSDM should be

Table 7 Inter-item correlation matrix for the German IcanSDM ( $n=242$ healthcare professionals).

\begin{tabular}{|c|c|c|c|c|c|c|c|c|}
\hline & Item 1 & Item 2 & Item 3 & Item 4 & Item 5 & Item 6 & Item 7 & Item 8 \\
\hline Item 1 & 1.000 & .165 & .128 & .158 & .266 & -.041 & .005 & .076 \\
\hline Item 2 & .166 & 1.000 & .132 & .171 & .252 & .084 & .282 & .277 \\
\hline Item 3 & .128 & .132 & 1.000 & .290 & .103 & .005 & .055 & .282 \\
\hline Item 4 & .158 & .171 & .290 & 1.000 & .412 & .245 & .228 & .234 \\
\hline Item 5 & .266 & .252 & .103 & .412 & 1.000 & .235 & .307 & .201 \\
\hline Item 6 & -.041 & .084 & -.005 & .245 & .235 & 1.000 & .392 & .119 \\
\hline Item 7 & .005 & .282 & .055 & .228 & .307 & .392 & 1.000 & .251 \\
\hline Item 8 & .076 & .277 & .282 & .234 & .201 & .119 & .251 & 1.000 \\
\hline
\end{tabular}




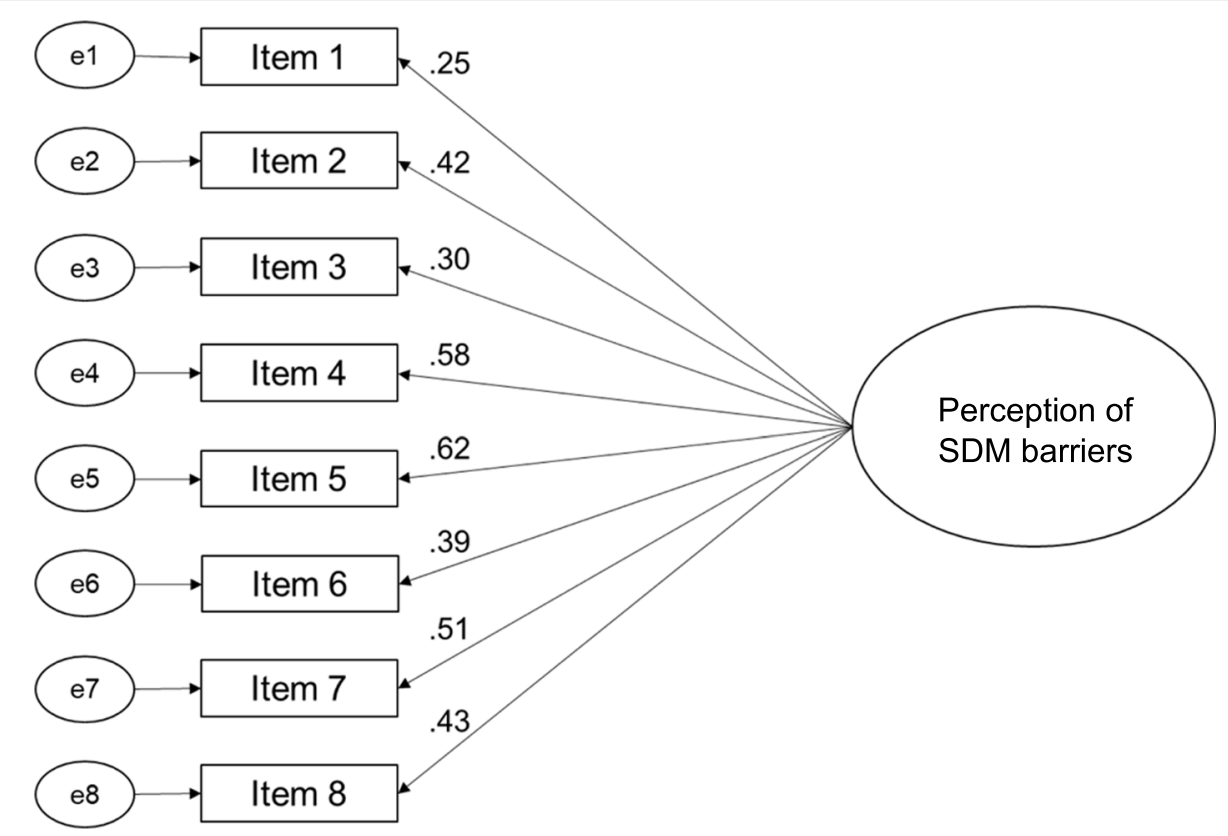

Fig. 2 Confirmatory factor analysis model for a one-factorial structure (model 1)

compared with actual and objectively measured SDM uptake by HCPs. Our SDM implementation study is a first step into this direction [22].

Furthermore, knowledge of HCPs' perceptions of SDM barriers can be helpful to prospectively plan a future SDM implementation study. IcanSDM results can be used to select suitable settings where SDM implementation might be most effective or to specifically address mostly perceived barriers.

\section{Strengths of this study}

We provided the first measure, which evaluated HCPs perception of SDM barriers in German language. The IcanSDM can be used in health services research and implementation studies. We followed an established translation procedure based on recommendations for cross-cultural translation studies. Additionally, we analysed comprehensibility of the items. For psychometric analysis we included physicians and nurses with diverse demographic characteristics. The sample size was adequate for conducting psychometric analysis.

\section{Limitations of this study}

This study has seven limitations. Since this was a secondary analysis of cross-sectional data, psychometric parameters like convergent or divergent validity were not analysable. Second, data collection was limited to three departments of one Comprehensive Cancer Centre in Germany. Because we did not hand over the survey to all participants personally, we cannot control that all eligible physicians and nurses received the survey. Furthermore, a self-selection bias of participants who are interested in the topic cannot be excluded. The psychometric properties of the IcanSDM are therefore not automatically transferable across translations and other settings. To make assumptions about generalizability, further validation in other settings is necessary. Third, we translated and adapted the English version of the

Table 8 Fit indices of three calculated models for factor analysis of the German IcanSDM ( $n=242$ healthcare professionals)

\begin{tabular}{|c|c|c|c|c|c|c|c|c|}
\hline & $\mathrm{Chi}^{2 \mathrm{a}}$ & $d f^{b}$ & $\mathrm{Chi}^{2} / \mathrm{df}^{\mathrm{c}}$ & $\mathrm{CFI}^{\mathrm{d}}$ & $\mathrm{TLI}^{\mathrm{e}}$ & RMSEA $^{f}$ & AIC $^{g}$ & PNFI $^{h}$ \\
\hline Model 1 & $72.48^{*}$ & 20 & 3.62 & .765 & .671 & .104 & 120.48 & .508 \\
\hline Model 2 & 45.51 & 18 & 2.53 & .878 & .808 & .080 & 97.51 & .526 \\
\hline Model 3 & 53.41 & 19 & 2.81 & .846 & .773 & .087 & 103.41 & .534 \\
\hline
\end{tabular}

Notes: Model 1 is a one-factor model with no correlations between items. Model 2 is a one-factor model with correlations between items 3 and 8 as well as items 6 and 7. Model 3 is a two-factor model with factor 1 including items 1 to 5 and 8 and factor 2 including item 6 and 7 . All models were calculated for the whole data set $(n=242)$

${ }^{a}$ Discrepancy chi-squared statistic, ${ }^{b}$ Degrees of freedom, ${ }^{c}$ Normed chi-squared statistic,

${ }^{d}$ Comparative fit indexes, ${ }^{e}$ Tucker-Lewis Index, ${ }^{f}$ Root mean square error of approximation, ${ }^{g}$ Akaike Information Criterion, ${ }^{\text {h }}$ Parsimonious Normed Fit Index (PNFI). ${ }^{*} p=.000$ 


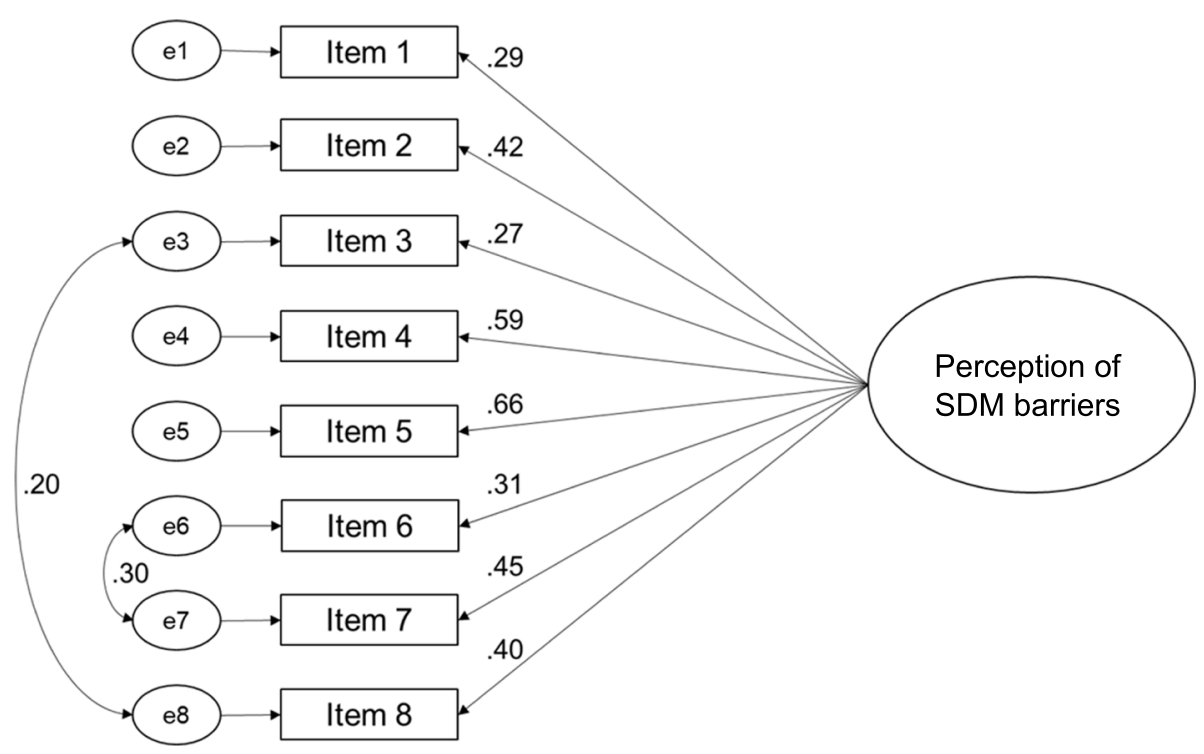

Fig. 3 Confirmatory factor analysis model for a one-factorial structure with correlations between items 3 and 8 as well as items 6 and 7 (model 2)

French IcanSDM. The English IcanSDM was translated for publication by an official translator and was not reviewed in a cross-cultural validation study. Thus, we did not translate and adapt the IcanSDM from its original language. Fourth, we had to assess a convenience sampling approach instead of a purposive sampling approach in cognitive interviews because it was difficult to recruit participants, especially physicians. Fifth, the final item 8 was not further tested in cognitive interviews, thus comprehensibility of this item remained unclear. Sixth, for handling missing data, we used mean replacement, which can lead to biased estimates. However, because the amount of missing data in our data set is very low $(0.62 \%)$, the probability of a potential bias

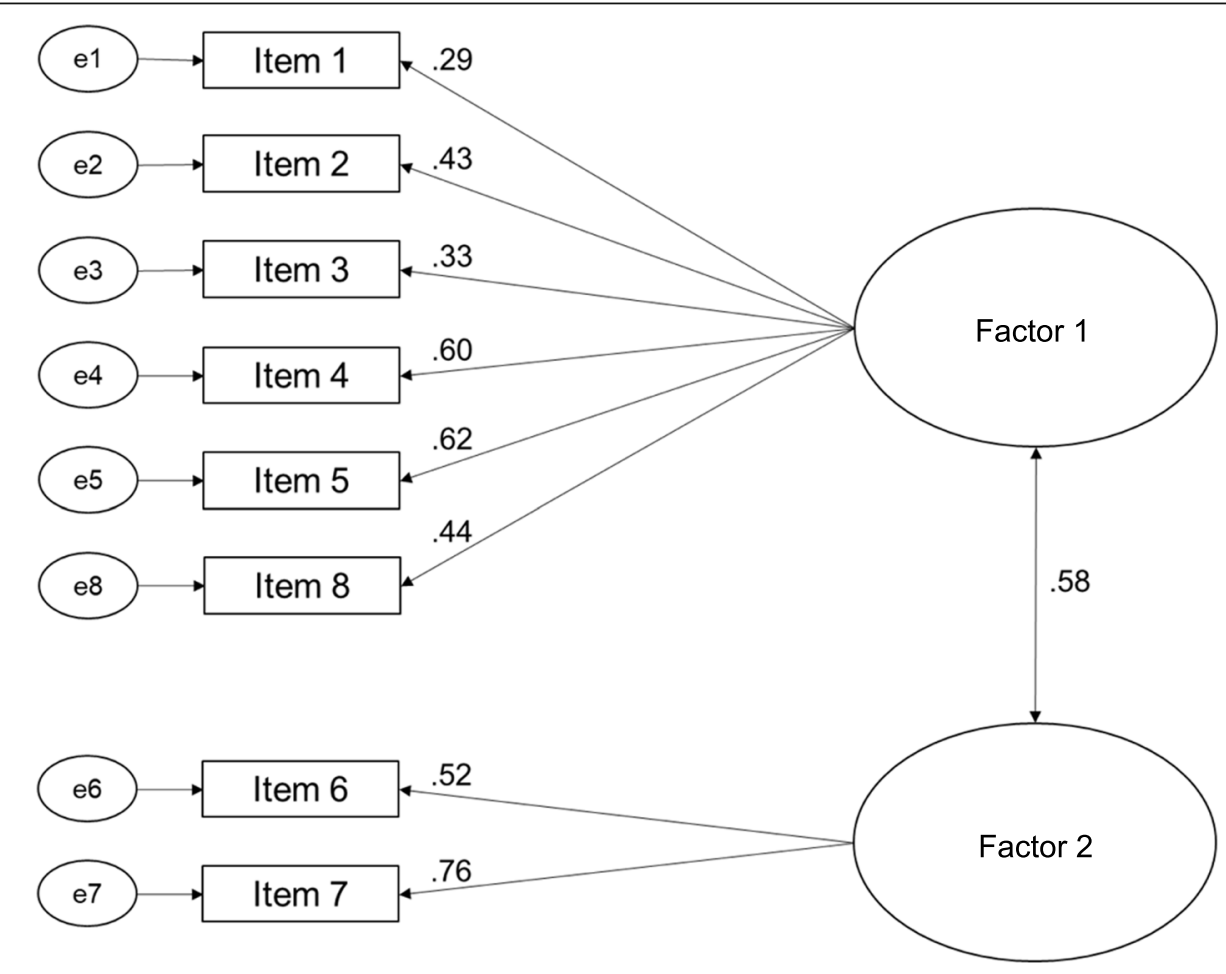

Fig. 4 Confirmatory factor analysis model for a two-factorial structure (model 3) 
should be quite low. Seventh, the results of the developmental process and psychometric evaluation of the French IcanSDM are not yet published in a peerreviewed journal. Since we conducted the first translation and psychometric evaluation of the French IcanSDM, other data on IcanSDM translations are missing.

\section{Conclusion}

HCPs' perceptions of SDM barriers should be measured with valid and reliable measures. We provide the first German measure for assessing this construct. The German IcanSDM is a brief measure with good acceptance. However, when assessing in a German hospital setting, we found unsatisfying psychometric properties, which were comparable to results of the original scale. Therefore, the German as well as the original IcanSDM need further revision and evaluation, especially regarding content validity. In a next step, predictive validity of the French and German IcanSDM should be evaluated. If the IcanSDM is further developed and revised successfully, it has the potential to assess perception of SDM barriers as predictors for SDM uptake in SDM implementation studies in German and international healthcare settings.

\section{Abbreviations}

AG: Anik Giguere; AIC: Akaike Information Criterion; AL: Anja Lindig; AMOS: Analysis of Moment Structure, Statistical Package for the Social Sciences, International Business Machines Corporation; Chi $^{2}$ : Discrepancy chisquared statistic; Chi2/df: Normed chi-squared statistic; CFI: Confirmatory fit index; Df: Degree of freedom; EC: Eva Christalle; HCP: Healthcare professional; IS: Isabelle Scholl; KMO: Kaiser-Meyer-Olkin criterion; MH: Martin Härter; NE: Nina Elpers; OK: Olaf von dem Knesebeck; PH: Pola Hahlweg; PNFI: Parsimonious Normed Fit Index; RMSEA: Root mean square error of approximation; SDM: Shared decision-making; SPSS: Statistical Package for the Social Sciences, International Business Machines Corporation; SZ: Stefan Zeh; TLI: Tucker-Lewis Index; TRAPD: Translation, Review, Adjudication, Pretesting, Documentation

\section{Supplementary Information}

The online version contains supplementary material available at https://doi. org/10.1186/s12913-021-06430-3.

Additional file 1. IcanSDM - German version.

\section{Acknowledgements}

We thank Anastasia Izotova, Sophia Schulte, and Nicolai Pergande for their help preparing the study and the analysis. We thank Nina Elpers and Stefan Zeh for their contribution to the team translation process. We thank Stefanie Heger for her contribution in preparing the manuscript. We also would like to thank Anik Giguere for giving the opportunity to translate the IcanSDM into German and to use it in our implementation study.

\section{Authors' contributions}

$\mathrm{AL}, \mathrm{PH}$, and IS made substantial contributions to the design and preparation of the study. AL, PH, IS and AG were involved in the translation and adaptation process. AL and $\mathrm{PH}$ collected the data for psychometric evaluation. AL conducted the analysis in collaboration with EC. All authors contributed to the interpretation of results. AL drafted the manuscript and $\mathrm{PH}, \mathrm{EC}, \mathrm{AG}, \mathrm{OK}, \mathrm{MH}$ and IS were involved in critically revising the manuscript for important intellectual content. All authors gave final approval of the version to be published.

\section{Funding}

This study is part of the study "Evaluation of a program for routine implementation of shared decision - making in cancer care: a stepped wedge cluster randomized trial", which is funded by the German Research Foundation (Deutsche Forschungsgemeinschaft, grant number 232160533). The funder had no influence on the design of the study, data collection and analysis, interpretation of data or writing the manuscript. Open Access funding enabled and organized by Projekt DEAL.

Availability of data and materials

The dataset collected and analyzed during this study is available from the corresponding author on reasonable request and after consultation of the Ethics Committee of the Medical Association Hamburg.

\section{Declarations}

\section{Ethics approval and consent to participate}

The study was approved by the Ethics Committee of the Medical Association Hamburg (Germany, study ID PV5368). The study was carried out in accordance to the latest version of the Helsinki Declaration of the World Medical Association. Principles of good clinical practice were respected. Data protection requirements were met. The psychometric evaluation of the IcanSDM was a secondary analysis of data gathered in the SDM implementation study. No administrative permission was required as all data were collected directly by the study team and no medical records were assessed.

\section{Consent for publication}

Not applicable.

\section{Competing interests}

$\mathrm{PH}$ gave one scientific presentation on shared decision-making during a lunch symposium in 2018, for which she received compensation and travel compensation from GlaxoSmithKline GmbH. AL, EC, AG, MH, OK and IS declared no competing interests.

\section{Author details}

${ }^{1}$ Department of Medical Psychology, University Medical Center Hamburg-Eppendorf, Martinistraße 52, 20246 Hamburg, Germany. ${ }^{2}$ Center of Health Care Research, University Medical Center Hamburg-Eppendorf, Martinistraße 52, 20246 Hamburg, Germany. ${ }^{3}$ Laval University Research Centre on Community-Based Primary Health Care (CERSSPL-UL), Québec City, QC, Canada. ${ }^{4}$ Department of Medical Sociology, University Medical Center Hamburg-Eppendorf, Martinistraße 52, 20246 Hamburg, Germany.

Received: 11 August 2020 Accepted: 23 April 2021

Published online: 02 June 2021

\section{References}

1. Wolfe A. Institute of Medicine report: crossing the quality chasm: a new health care system for the 21st century. Policy Polit Nurs Pract. 2001;2(3): 233-5.

2. Zill JM, Scholl I, Härter M, Dirmaier J. Which dimensions of patientcenteredness matter? - results of a web-based expert delphi survey. PLoS One. 2015;10(11):e0141978. https://doi.org/10.1371/journal.pone.0141978.

3. Härter M, Dirmaier J, Scholl I, Donner-Banzhoff N, Dierks ML, Eich W, et al. Der lange Weg zur Implementierung patientenzentrierter Versorgung und partizipativer Entscheidungsfindung in Deutschland. Z Evid Fortbild Qual Gesundhwes. 2017;123-124:46-51.

4. Clayman ML, Bylund CL, Chewning B, Makoul G. The impact of patient participation in health decisions within medical encounters: a systematic review. Med Decis Mak. 2016;36(4):427-52. https://doi.org/10.1177/0272 989X15613530.

5. Härter M, Müller H, Dirmaier J, Donner-Banzhoff N, Bieber C, Eich W. Patient participation and shared decision making in Germany - history, agents and current transfer to practice. Z Evid Fortbild Qual Gesundhwes. 2011;105(4): 263-70. https://doi.org/10.1016/j.zefq.2011.04.002. 
6. Bieber C, Gschwendtner K, Müller N, Eich W. Partizipative Entscheidungsfindung (PEF) - Patient und Arzt als Team. Rehabilitation. 2017;56(03):198-213.

7. Härter M, Buchholz A, Nicolai J, Reuter K, Komarahadi F, Kriston L, et al. Shared decision making and the use of decision aids. Dtsch Arztebl Int. 2015;112(40):672-9. https://doi.org/10.3238/arztebl.2015.0672.

8. Bieber C, Loh A, Ringel N, Eich W, Härter M. Patientenbeteiligung bei medizinischen Entscheidungen. Manual zur partizipativen Entscheidungsfindung (Shared Decision-Making). Freiburg: Universitätsklinikum Freiburg; 2007.

9. Salzburg Global Seminar. Salzburg statment on shared decision making BMJ. 2011;342(342):1745.

10. Reuter K, Loh A, Härter M. Patient as partner in oncology - opportunities for shared decision-making. In: Koch U, Weis J, editors. Psycho-oncology - a discipline in development. Göttingen: Hogrefe; 2009. p. 131-45.

11. Hahlweg P, Kriston L, Scholl I, Brähler E, Faller H, Schulz H, et al. Cancer patients' preferred and perceived level of involvement in treatment decision-making. Acta Oncol. 2020;59(8):967-74. https://doi.org/10.1080/02 84186X.2020.1762926.

12. Hauser K, Koerfer A, Kuhr K, Albus C, Herzig S, Matthes J. Outcome-relevant effects of shared decision making. Dtsch Arztebl Int. 2015;112(40):665-71.

13. Shay LA, Lafata JE. Where is the evidence? A systematic review of shared decision making and patient outcomes. Med Decis Mak. 2015;35(1):114-31. https://doi.org/10.1177/0272989X14551638.

14. Härter M, Moumjid N, Cornuz J, Elwyn G, van der Weijden T. Shared decision making in 2017: international accomplishments in policy, research and implementation. Z Evid Fortbild Qual Gesundhwes. 2017;123-124:1-5.

15. Ernst J, Brahler E, Weissflog G. Patient involvement in medical decision making--an overview on patient preferences and impacting factors. Gesundheitswesen. 2014;76(4):187-92. https://doi.org/10.1055/s-0033-1361150.

16. Chewning B, Bylund CL, Shah B, Arora NK, Gueguen JA, Makoul G. Patient preferences for shared decisions: a systematic review. Patient Educ Couns. 2012;86(1):9-18. https://doi.org/10.1016/j.pec.2011.02.004.

17. Brom L, Hopmans W, Pasman HR, Timmermans D, Widdershoven G, Onwuteaka-Philipsen B. Congruence between patients' preferred and perceived participation in medical decision-making: a review of the literature. BMC Med Inform Decis Mak. 2014;14(1):25. https://doi.org/10.11 86/1472-6947-14-25.

18. Chekerov R, Harter P, Fuxius S, Hanker LC, Woelber L, Müller L, et al. Preference of elderly patients' to oral or intravenous chemotherapy in heavily pre-treated recurrent ovarian cancer: final results of a prospective multicenter trial. Gynecol Oncol Res Pract. 2017;4(1):6. https://doi.org/10.11 86/s40661-017-0040-2

19. Couët N, Desroches S, Robitaille H, Vaillancourt H, Leblanc A, Turcotte S, et al. Assessments of the extent to which health-care providers involve patients in decision making: a systematic review of studies using the OPTION instrument. Health Expect. 2015;18(4):542-61. https://doi.org/1 0.1111/hex.12054.

20. Frosch D, Tietbohl C, Scholl I. Overcoming implementation challenges to advance shared-decision making in routine practice. In: Elwyn $G$, Thompson $R$, Edwards A, editors. Shared decision making in health care: achieving evidence-based patient choice. 3rd ed. Oxford: Oxford University Press; 2016. https://doi.org/10.1093/acprof:oso/9780198723448.003.0004.

21. Légaré F, Ratté $S$, Gravel K, Graham ID. Barriers and facilitators to implementing shared decision-making in clinical practice: update of a systematic review of health professionals' perceptions. Patient Educ Couns. 2008;73(3):526-35. https://doi.org/10.1016/j.pec.2008.07.018.

22. Scholl I, Hahlweg P, Lindig A, Bokemeyer C, Coym A, Hanken H, et al. Evaluation of a program for routine implementation of shared decisionmaking in cancer care : study protocol of a stepped wedge cluster randomized trial. Implement Sci. 2018;13(51):1-10.

23. Légaré $F$, Thompson-Leduc $P$. Twelve myths about shared decision making. Patient Educ Couns. 2014;96(3):281-6. https://doi.org/10.1016/j.pec.2014.06.014.

24. Elwyn G, Scholl I, Tietbohl C, Mann M, Edwards AGK, Clay C, et al. "Many miles to go...": A systematic review of the implementation of patient decision support interventions into routine clinical practice. BMC Med Inform Decis Mak. 2013;13(Suppl. 2):14.

25. Friedberg MW, Van Busum K, Wexler R, Bowen M, Schneider EC. A demonstration of shared decision making in primary care highlights barriers to adoption and potential remedies. Health Aff. 2013;32(2):268-75. https:// doi.org/10.1377/hlthaff.2012.1084
26. Scholl I, LaRussa A, Hahlweg P, Kobrin S, Elwyn G. Organizational- and system-level characteristics that influence implementation of shared decision-making and strategies to address them - a scoping review. Implement Sci. 2018;13(1):40. https://doi.org/10.1186/s13012-018-0731-z.

27. Krupat E, Rosenkranz SL, Yeager CM, Barnard K, Putnam SM, Inui TS. The practice orientations of physicians and patients: the effect of doctor-patient congruence on satisfaction. Patient Educ Couns. 2000;39(1):49-59. https:// doi.org/10.1016/S0738-3991(99)00090-7.

28. Ajzen I, Fishbein M. The influence of attitudes on behavior. In: Albarracín D, Johnson BT, Zanna MP, editors. The handbook of attitudes. Mahwah: Lawrence Erlbaum Associates; 2005. p. 173-221.

29. Ajzen I. The theory of planned behavior. Organ Behav Hum Decis Process. 1991;50(2):179-211. https://doi.org/10.1016/0749-5978(91)90020-T.

30. Eccles MP, Hrisos S, Francis J, Kaner EF, Dickinson HO, Beyer F, et al. Do selfreported intentions predict clinicians' behaviour: a systematic review. Implement Sci. 2006;1:28.

31. Hoffmann TC, Bennett S, Tomsett C, Del Mar C. Brief training of student clinicians in shared decision making: a single-blind randomized controlled trial. J Gen Intern Med. 2014;29(6):844-9. https://doi.org/10.1007/s11606014-2765-5

32. Müller E, Strukava A, Scholl I, Härter M, Diouf NT, Légaré F, et al. Strategies to evaluate healthcare provider trainings in shared decision-making (SDM): a systematic review of evaluation studies. BMJ Open. 2019;9(6):e026488. https://doi.org/10.1136/bmjopen-2018-026488.

33. Forcino RC, West Yen R, Aboumrad M, Barr PJ, Schubbe D, Elwyn G, et al. US-based cross-sectional survey of clinicians' knowledge and attitudes about shared decision-making across healthcare professions and specialties. BMJ Open. 2018;8:e022730.

34. Elwyn G, Rasmussen J, Kinsey K, Firth J, Marrin K, Edwards A, et al. On a learning curve for shared decision making: interviews with clinicians using the knee osteoarthritis Option grid. J Eval Clin Pract. 2018;24(1):56-64. https://doi.org/10.1111/jep.12665.

35. Giguere AM, Bogza L-M, Coudert L, Carmichael P-H, Renaud J-S, Légaré F, et al. Development of the IcanSDM scale to assess primary care clinicians' ability to adopt shared decision making. medRxiv 2020.07.01.20144204. https://doi.org/10.1101/2020.07.01.20144204

36. Scholl I, Koelewijn-van Loon M, Sepucha K, Elwyn G, Légaré F, Härter M, et al. Measurement of shared decision making - a review of instruments. Z Evid Fortbild Qual Gesundhwes. 2011;105(4):313-24. https://doi.org/10.1016/ j.zefq.2011.04.012.

37. Herdman M, Fox-Rushby J, Badia X. A model of equivalence in the cultural adaptation of HRQoL instruments: the universalist approach. Qual Life Res. 1998;7(4):323-35. https://doi.org/10.1023/A:1008846618880.

38. Gjersing L, Caplehorn JRM, Clausen T. Cross-cultural adaptation of research instruments: language, setting, time and statistical considerations. BMC Med Res Methodol. 2010;10:13.

39. Squires A, Aiken LH, van den Heede K, Sermeus W, Bruyneel L, Lindqvist R, et al. A systematic survey instrument translation process for multi-country, comparative health workforce studies. Int J Nurse Stud. 2013;50(2):264-73. https://doi.org/10.1016/j.ijnurstu.2012.02.015.

40. Craig P, Dieppe P, Macintyre S, Michie S, Nazareth I, Petticrew M. Developing and evaluating complex interventions: the new Medical Research Council guidance. Int J Nurs Stud. 2013;50(5):587-92. https://doi. org/10.1016/j.jijnurstu.2012.09.010.

41. Mdege ND, Man MS, Taylor CA, Torgerson DJ. Systematic review of stepped wedge cluster randomized trials shows that design is particularly used to evaluate interventions during routine implementation. J Clin Epidemiol. 2011;64(9):936-48. https://doi.org/10.1016/j.jclinepi.2010.12.003.

42. Lindig A, Hahlweg P, Christalle E, Scholl I. Translation and psychometric evaluation of the German version of the Organisational readiness for implementing change measure (ORIC): a cross-sectional study. BMJ Open. 2020;10(6):e034380. https://doi.org/10.1136/bmjopen-2019-034380.

43. Graham ID, Logan J. Innovations in knowledge transfer and continuity of care. CJNR. 2004;36(2):89-103.

44. Perneger TV, Leplège A, Etter JF. Cross-cultural adaptation of a psychometric instrument: two methods compared. J Clin Epidemiol. 1999;52(11):1037-46. https://doi.org/10.1016/S0895-4356(99)00088-8.

45. Epstein J, Osborne RH, Elsworth GR, Beaton DE, Guillemin F. Cross-cultural adaptation of the health education impact questionnaire: experimental study showed expert committee, not back-translation, added value. J Clin Epidemiol. 2015;68(4):360-9. https://doi.org/10.1016/j.jclinepi.2013.07.013. 
46. Forcino RC, Bustamante N, Thompson R, Percac-Lima S, Elwyn G, Pe'rezArechaederra D, et al. Developing and Pilot Testing a Spanish Translation of CollaboRATE for Use in the United States. PLoS One. 2016;11(12):e0168538.

47. Harkness J, Pennell BE, Schoua-Glusberg A. Survey Questionnaire Translation and Assessment. In: Presser S, Rothgeb J, Couper M, Lessler J, Martin E, Martin J, et al., editors. Methods for Testing and Evaluating Survey Questionnaires. Hoboken: Wiley; 2004. p. 453-73.

48. Terwee CB, Prinsen CAC, Chiarotto A, Westerman MJ, Patrick DL, Alonso J, et al. COSMIN methodology for evaluating the content validity of patientreported outcome measures: a Delphi study. Qual Life Res. 2018;27(5):115970. https://doi.org/10.1007/s11136-018-1829-0.

49. Mokkink LB, Terwee CB, Patrick DL, Alonso J, Stratford PW, Knol DL, et al. The COSMIN study reached international consensus on taxonomy, terminology, and definitions of measurement properties for health-related patient-reported outcomes. J Clin Epidemiol. 2010;63(7):737-45. https://doi. org/10.1016/j.jclinepi.2010.02.006.

50. Willis GB. Cognitive interviewing. A tool for improving questionnaire design. Thousand Oaks: Sage Publications; 2005. https:/doi.org/10.4135/9781412983655.

51. Willis GB, Research Triangle Institute. Cognitive interviewing - a "how to" guide. 1999

52. Degner LF, Sloan JA, Venkatesh P. The control preferences scale. Can J Nurs Res. 1997;29(3):21-43.

53. Lindig A, Hahlweg P, Christalle E, Scholl I. Translation and psychometric evaluation of the German version of the organizational readiness for implementing change measure (ORIC) - a cross-sectional study. BMJ Open. 2020;10(6):e034380. https://doi.org/10.1136/bmjopen-2019-034380.

54. Hahlweg $P$, Härter $M$, Nestoriuc $Y$, Scholl I. How are decisions made in cancer care? A qualitative study using participant observation of current practice. BMJ Open. 2017;7(9):e016360. https://doi.org/10.1136/bmjopen-201 7-016360.

55. Bannon WJ. Missing data within a quantitative research study: how to assess it, treat it, and why you should care. J Am Assoc Nurse Pr. 2015;27(4): 230-2. https://doi.org/10.1002/2327-6924.12208.

56. McHorney CA, Tarlov AR. Individual-patient monitoring in clinical practice: are available health status surveys adequate? Qual Life Res. 1995;4(4):293307. https://doi.org/10.1007/BF01593882.

57. Streiner DL, Norman GR, Cairney J. Health measurement scales: a practical guide to their development and use; 2015.

58. Bortz J, Döring N. Forschungsmethoden und evaluation. 4th ed. Heidelberg: Springer; 2006. https://doi.org/10.1007/978-3-540-33306-7.

59. Tabachnick BG, Fidell LS. Using multivariate statistics. 5th ed. Essex: Pearson Education Inc:; 2013

60. Rattray J, Jones MC. Essential elements of questionnaire design and development. J Clin Nurs. 2007;16(2):234-43. https://doi.org/10.1111/j.1365-2 702.2006.01573.x.

61. Ferketich S. Focus on psychometrics. Aspects of item analysis. Res Nurs Health. 1991;14(2):165-8. https://doi.org/10.1002/nur.4770140211.

62. Field A. Discovering statistics using SPSS. 2nd ed. London: SAGE Publications Ltd; 2005.

63. Hair J, Black W, Babin B, Anderson RE. Multivariate data analysis. Upper Saddle River: Pearson Prentice Hall; 2009.

64. Stevens JP. Applied multivariate statistics for the social sciences. 2nd ed. Hillsdale: Erlbaum; 1992.

65. Hooper D, Coughlan J, Mullen M. Structural Equation Modelling: Guidelines for Determining Model Fit. Articles; 2008.

66. Hu L, Bentler P. Cutoff criteria for fit indexes in covariance structure analysis: conventional criteria versus new alternatives. Struct Eq Model. 1999;6(1):155. https://doi.org/10.1080/10705519909540118.

67. Schermelleh-Engel $\mathrm{K}$, Moosbrugger $\mathrm{H}$, Müller $\mathrm{H}$. Evaluating the fit of structural equation models: tests of significance and descriptive goodnessof-fit measures. Meth Psychol Res Online. 2003;8:23-74.

68. Bentler PM. Comparative fit indexes in structural models. Psychol Bull. 1990; 107(2):238-46. https://doi.org/10.1037/0033-2909.107.2.238.

69. Browne MW, Cudeck R. Single sample cross-validation indices for covariance structures. Multivariate Behav Res. 1989;24(4):445-55. https://doi.org/10.12 07/s15327906mbr2404_4.

70. Bannigan K, Watson R. Reliability and validity in a nutshell. J Clin Nurs. 2009; 18(23):3237-43. https://doi.org/10.1111/j.1365-2702.2009.02939.x.

71. Härter M, van der Weijden T, Elwyn G. Policy and practice developments in the implementation of shared decision making: an international perspective.
Z Evid Fortbild Qual Gesundhwes. 2011;105(4):229-33. https://doi.org/10.101 6/j.zefa.2011.04.018.

72. Raspe H, Pfaff H, Härter M, Hart D, Koch-Gromus U, Schwartz FW, et al. Health-services research in Germany: statement on current state - prospects - promotion. Bonn: Deutsche Forschungsgemeinschaft; 2010. p. 50.

73. Kölker M, Topp J, Elwyn G, Härter M, Scholl I. Psychometric properties of the German version of Observer OPTION5. BMC Health Serv Res. 2018;18(1):74.

74. Härter M, Dirmaier J, Scholl I, Donner-Banzhoff N, Dierks M-L, Eich W, et al. The long way of implementing patient-centered care and shared decision making in Germany. Z Evid Fortbild Qual Gesundhwes. 2017;123-124:46-51.

75. Mathijssen EGE, van den Bemt BJF, Wielsma S, van den Hoogen FHJ, Vriezekolk JE. Exploring healthcare professionals' knowledge, attitudes and experiences of shared decision making in rheumatology. RMD Open. 2020; 6(1):e001121. https://doi.org/10.1136/rmdopen-2019-001121.

76. Topp J, Westenhöfer J, Scholl I, Hahlweg P. Shared decision-making in physical therapy: A cross-sectional study on physiotherapists' knowledge, attitudes and self-reported use. Patient Educ Couns. 2017. https://doi.org/1 0.1016/j.pec.2017.07.031

77. Bieber C, Nicolai J, Hartmann M, Blumenstiel K, Ringel N, Schneider A, et al. Training physicians in shared decision-making — who can be reached and what is achieved? Patient Educ Couns. 2009;77(1):48-54. https://doi.org/10.1 016/j.pec.2009.03.019.

78. Warzyniec A, Tariman JD, Simonovich S. Shared decision making: effects of an online education session on knowledge, attitudes, adaptability, and communication skills among nurses. Clin J Oncol Nurs. 2019;23(6):E93-9. https://doi.org/10.1188/19.CJON.E93-E99.

79. Chung M-C, Juang W-C, Li Y-C. Perceptions of shared decision making among health care professionals. J Eval Clin Pract. 2019;25(6):1080-7. https://doi.org/10.1111/jep.13249.

\section{Publisher's Note}

Springer Nature remains neutral with regard to jurisdictional claims in published maps and institutional affiliations.
Ready to submit your research? Choose BMC and benefit from:

- fast, convenient online submission

- thorough peer review by experienced researchers in your field

- rapid publication on acceptance

- support for research data, including large and complex data types

- gold Open Access which fosters wider collaboration and increased citations

- maximum visibility for your research: over $100 \mathrm{M}$ website views per year

At BMC, research is always in progress.

Learn more biomedcentral.com/submissions 